\title{
Effect of ionic strength on the formal potential of the glass electrode in various saline media
}

Isabel Brandariz ${ }^{\mathrm{a}}$, Teresa Vilariño ${ }^{\mathrm{a}}$, Pablo Alonso $^{\mathrm{a}}$, Roberto Herrero ${ }^{\mathrm{a}}$, Sarah Fiol $^{\mathrm{b}}$, Manuel E. Sastre de Vicente ${ }^{\mathrm{a}}$,

Talanta,

Volume 46, Issue 6, August 1998, Pages 1469-1477

Received 27 May 1997, Revised 21 October 1997, Accepted 19 December 1997, Available online 4 December 1998

DOI:10.1016/S0039-9140(98)00022-8

\begin{abstract}
We examined the variation with ionic strength ( $I$, adjusted with $\mathrm{KCl}, \mathrm{KNO}_{3}, \mathrm{KBr}, \mathrm{NaCl}$ or $\mathrm{NaClO}_{4}$ ) of the formal potential $\left(E_{\text {const }}\right)$ for glass electrodes exhibiting a Nernstian response (i.e. $E_{\text {cell }}=E_{\text {const }}-S \log \left[\mathrm{H}^{+}\right]$). For this purpose, we investigated the different factors included in the formal potential, so we obtained reported values for the liquid junction potential as a function of ionic strength and determined the logarithm of the activity coefficient for the proton in various saline media, using Pitzer equations.
\end{abstract}

\section{Keywords}

Ionic strength; Formal potential; Glass electrode; Potentiometry

\footnotetext{
a Departamento de Química Fundamental e Industrial, Facultad de Ciencias, Universidad de La Coruña, Campus da Zapateira s/n, E-15701 La Coruña, Spain

${ }^{\mathrm{b}}$ Departamento de Química Física, Facultad de Química, Universidad de Santiago de Compostela, E-15706 Santiago de Compostela, Spain
} 


\section{Theoretical background}

Potentiometry with a commercially available $\mathrm{H}^{+}$ion-sensitive glass electrode, also referred to as 'pH-metry', is a powerful tool for determining equilibrium constants [1]. IUPAC recommends calibrating glass electrodes in terms of the proton concentration at a constant ionic strength prior to the determination proper [2]. Glass electrodes exhibit a Nernstian response; consequently, the resulting electromotive force at constant ionic strength will be given by [3]

$$
E_{\text {cell }}=E_{\text {corrst }}(I)+s \log \left[\mathrm{H}^{+}\right]
$$

where

$$
E_{\text {const }}=E_{\mathrm{T}}+E_{\mathrm{l}}+E_{g}^{o}+\mathrm{s} \log \gamma_{\mathrm{H}}+
$$

and $s$ denotes the Nernstian slope, the value of which at $25^{\circ} \mathrm{C}$ is

$$
s=\ln 10 R T / F=59.16 \mathrm{mV}
$$

In Eq. (2), $E_{\mathrm{g}}{ }^{0}$ is the potential across the glass membrane at unity proton activity; $E_{\mathrm{r}}$ is the combination of the external and internal reference potentials and will thus be independent of the ionic strength of the unknown solution-unlike the liquid junction potential $\left(E_{1}\right)$ and, obviously, the activity coefficient for the proton $\left(\log \gamma_{\mathrm{H}}{ }^{+}\right)$. According to the Stockholm school [4], $E_{1}$ varies with acidity; however, several authors have shown that it can be assumed not to vary, within experimental errors, with small acidity changes (e.g. over the $-\log \left[\mathrm{H}^{+}\right]$ranges $2.3-2.9$ and 10.8-11.3). In addition, fulfillment of Eq. (1)has been experimentally confirmed 3 and 5 .

Parameter $E_{\mathrm{g}}{ }^{0}$ encompasses the asymmetry potential, resulting from differences between the inner and outer leached layers and potentially arising from composition differences introduced during the electrode's manufacturing process, a differential history for both leached layers or the adsorption of given substances by either [6].

Although formal potentials, $E_{\text {const, }}$ are commonly used to determine equilibrium constants, virtually none of the studies involving calibration of glass electrodes in terms of the proton concentration 7, 8,9,10,11 and 12has reported on the variation of $E_{\text {const }}$ with ionic strength [ $\left.E_{\text {const }}=f(I)\right]$. One interesting exception is the study of Pezza et al. [13], who used various ion-selective electrodes to determine the activity coefficients for the ions sensed by each electrode. In this work, we used commercially available $\mathrm{H}^{+}$ion-sensitive glass electrodes to compare the variation of the formal potential with ionic strength in five different electrolytes that are commonly used to adjust the latter parameter $\left(\mathrm{NaCl}, \mathrm{KCl}, \mathrm{KBr}, \mathrm{KNO}_{3}\right.$ and $\left.\mathrm{NaClO}_{4}\right)$. 


\section{Experimental}

Calibrations were done in an acid medium $^{1}$ as described elsewhere [5]:variable volumes $v$ of a strong acid of concentration $c$ were successively added to an initial volume $V_{0}$ of inert electrolyte solution. The proton concentration was thus given by

$$
\left[\mathrm{H}^{+}\right]=\frac{c v}{V_{0}+v}
$$

where $2.3<-\log \left[\mathrm{H}^{+}\right]<2.9$ [3]. We used an initial volume $V_{0}=40.0 \mathrm{ml}$ to which $0.04 \mathrm{ml}$ aliquots of $0.1000 \mathrm{M} \mathrm{HCl}$ were successively added. Only those points included in the above-mentioned range were used to fit $E_{\text {cell }}$ versus $\log \left[\mathrm{H}^{+}\right]$curves.

We carried out experiments at a variable ionic strength adjusted with $\mathrm{NaCl}, \mathrm{KBr}, \mathrm{KNO}_{3}$, $\mathrm{KCl}$ and $\mathrm{NaClO}_{4}$ (all Merck p.a. reagents). The water used to prepare every solution was purified by passage through a Millipore Milli-Q system. All experiments were performed in a dual-wall cell through which water thermostated at $25.0 \pm 0.1^{\circ} \mathrm{C}$ was circulated. Nitrogen of $99.999 \%$ purity was bubbled through the cell to remove $\mathrm{CO}_{2}$ and stir the solution. A Crison microBU 2030 autoburette furnished with a $2.5 \mathrm{ml}$ syringe for dispensing the titrant was used. The burette was controlled via a computer that afforded reading the emf of a Crison micropH $2002 \mathrm{pH}$-meter connected to a Radiometer GK2401C electrode. This last was a glass electrode combined with an $\mathrm{Ag} / \mathrm{AgCl}$ reference electrode where the liquid junction was established by a salt bridge consisting of a plug of porous ceramics.

\section{Results and discussion}

Fig. 1 shows a typical calibration curve, of intercept $E_{\text {const }}=378.9 \pm 0.1 \mathrm{mV}$ and slope $59.1 \pm 0.1 \mathrm{mV}$. The $E_{\text {const }}$ values obtained from similar fitted curves for the different electrolytes are shown in Fig. 2 Fig. 4 and Fig. 5. By way of example, Fig. 3 shows the slopes of the calibration curves obtained in $\mathrm{KNO}_{3}$; as can be seen, there were no significant deviations from $59.2 \mathrm{mV}$ at $25^{\circ} \mathrm{C}$ - the largest error was $2 \%$-, which testifies to the Nernstian behaviour of the electrode. Similar results were obtained regarding the slopes of the fitted curves for the other electrolytes. On the other hand, careful examination of Fig. 2 reveals increased dispersion of formal potentials in graph D. The difference arose from the fact that, except in series 1D, the glass electrode was stored in a slightly acidic solution (about $0.05 \mathrm{M}$ ) while not in use in order to improve its response relative to storage in water or a neutral buffer [14]. During the calibrations of Fig. 2D, the electrode was kept in distilled water while not in use - an identical behaviour was observed if it was stored in a neutral buffer. 


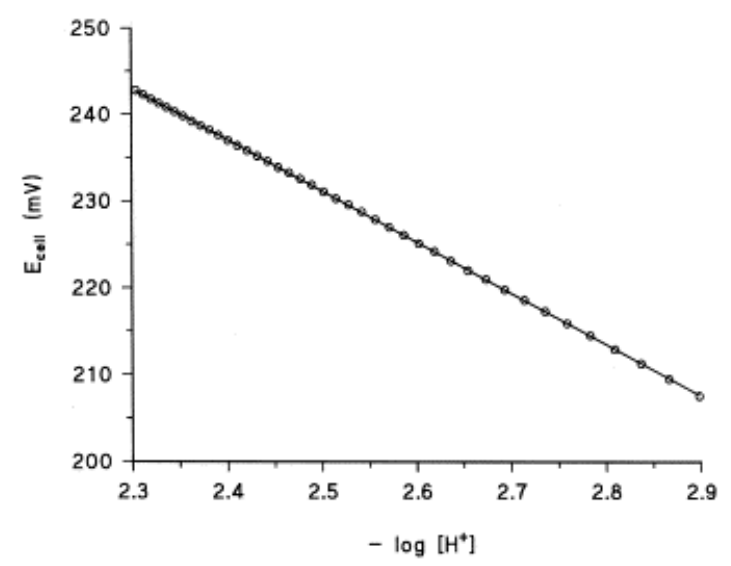

Fig. 1.

Calibration curve of equation $E=378.9$ ( \pm $0.1)-59.1( \pm 0.1) \mathrm{p}\left[\mathrm{H}^{+}\right]$in $0.6 \mathrm{M} \mathrm{KBr}$.
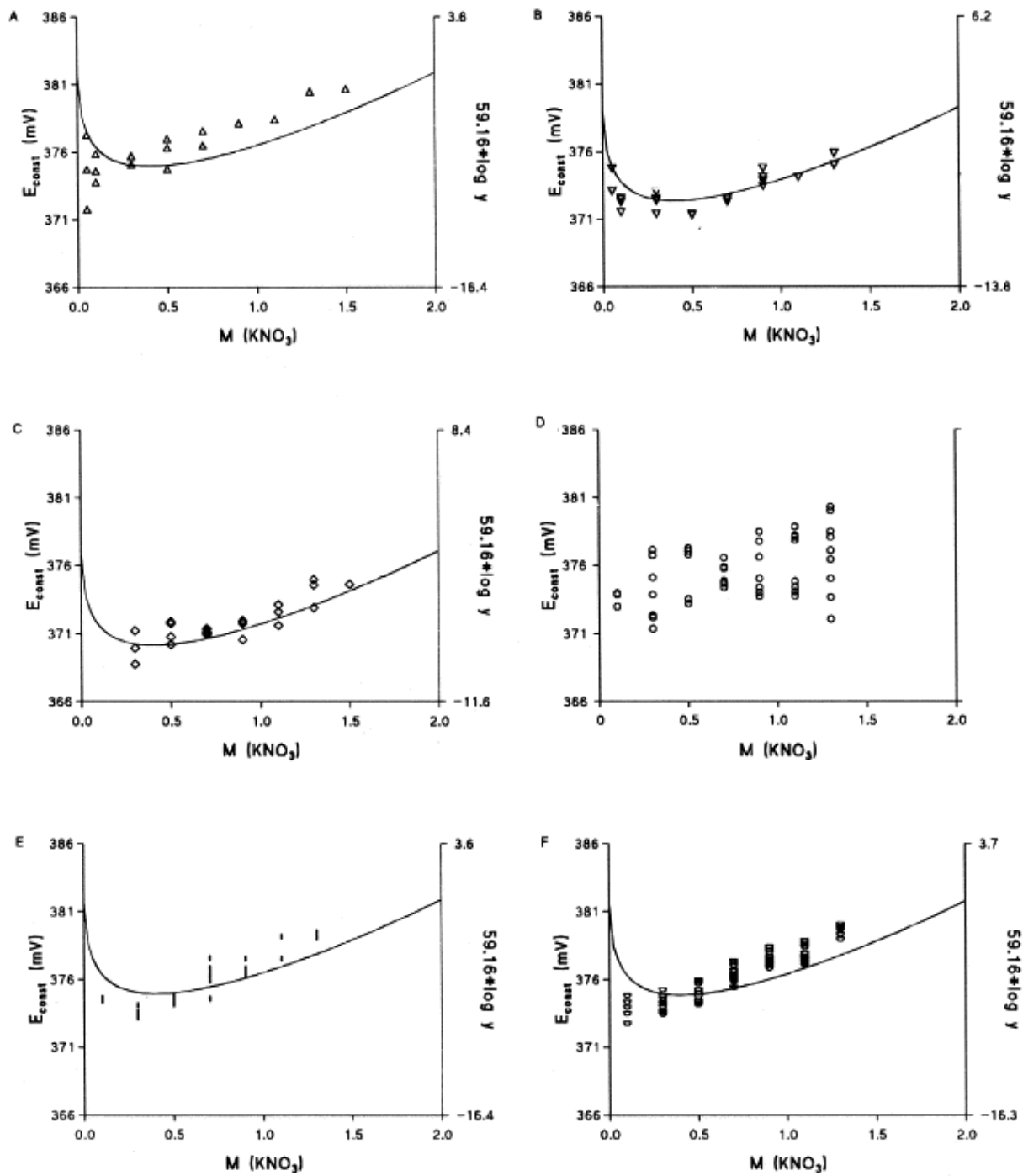

Fig. 2. Variation of $E_{\text {const }}$ with $I$ in $\mathrm{KNO}_{3}$. Data obtained with the same Radiometer GK2401C electrode on the following time frames: (A) May-June, 1992, (B) April, 1993, (C) JanuaryApril, 1994, (D) October, 1994, (E) December, 1994, and (F) February-March, 1995. The solid line represents the variation of $s \log \gamma_{\mathrm{H}}{ }^{+}$with $I$ according to the Pitzer equations. 


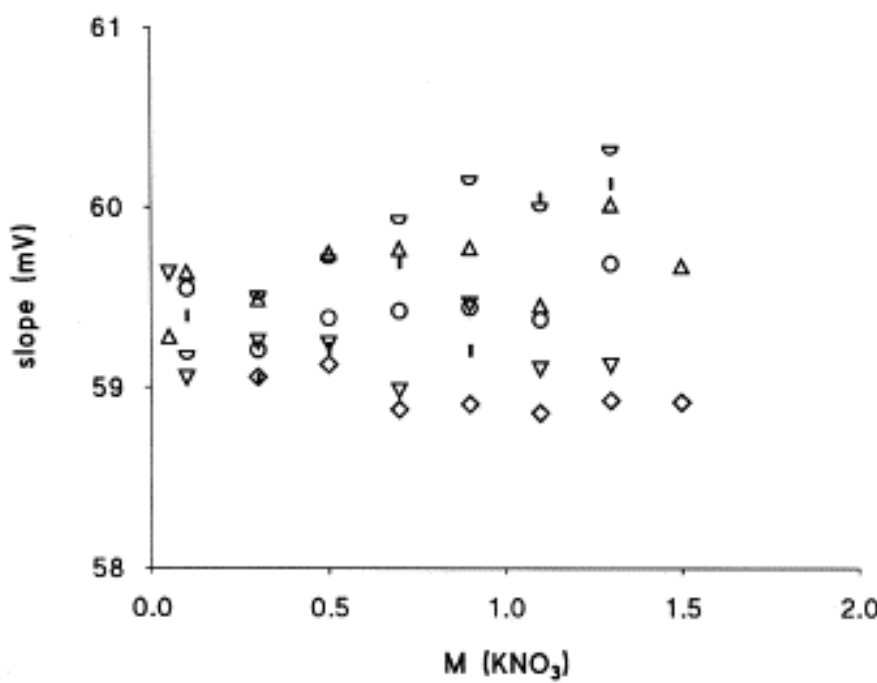

Fig. 3.

Mean of the slopes of the calibration curves in Fig. 2.

As can also be seen from Fig. 2, experimental points in the $E_{\text {const }}$ versus $I$ graphs followed the same pattern, albeit shifted to lower or higher potentials - note that the same scale was used in all graphs.

In order to account for the behaviour of these $E_{\text {const }}$ versus $I$ curves in Fig. 2 and Fig. 4 Fig. 5 one must break down $E_{\text {const }}$ into the factors included in Eq. (2). As noted earlier, both the liquid junction potential, $E_{1}$, and the activity coefficient for the proton, vary with ionic strength.

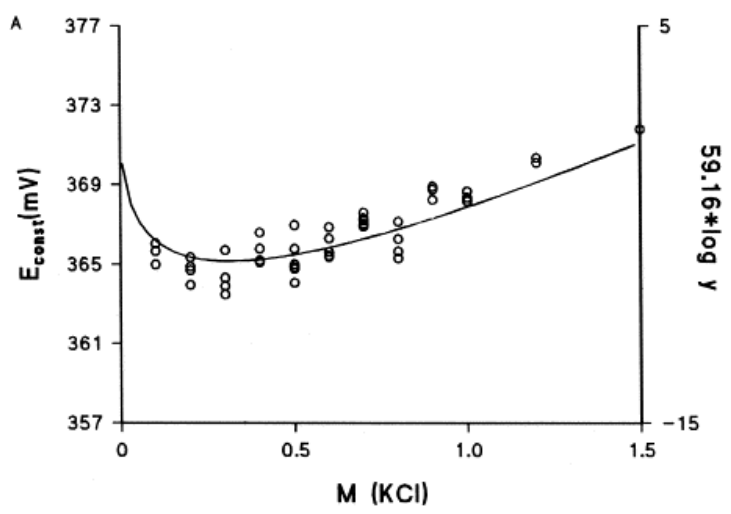

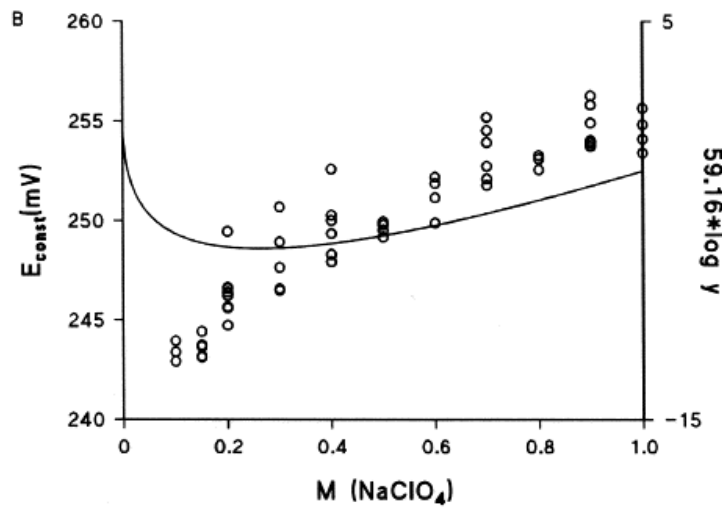

Fig. 4.

Variation of $E_{\text {const }}$ with $I$ in the following electrolytes: (A) $\mathrm{KCl}$ and (B) $\mathrm{NaClO}_{4}$. The solid line represents the variation of $s \log \gamma_{\mathrm{H}}{ }^{+}$with $I$ according to the Pitzer equations. 

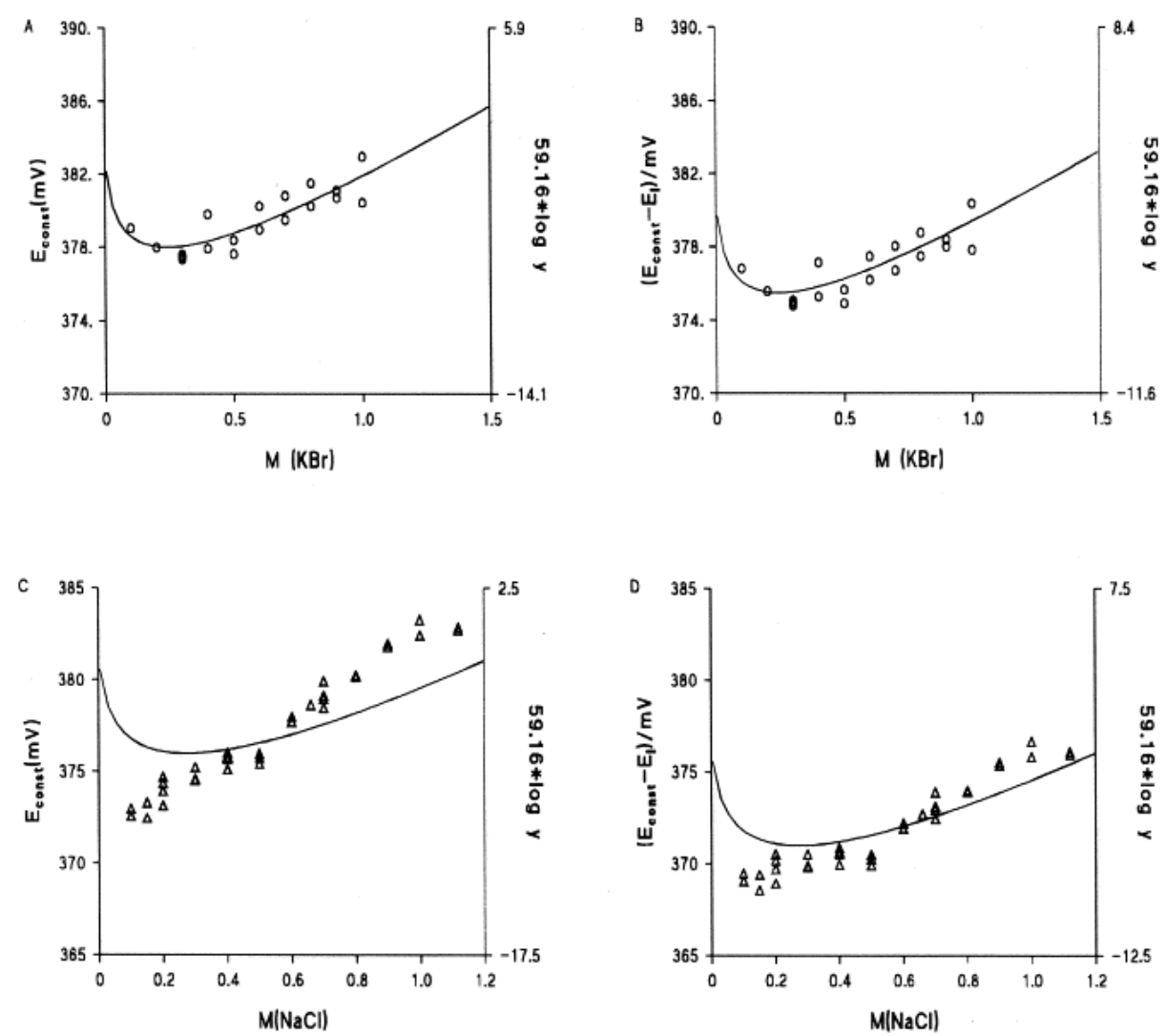

Fig. 5.

Variation of (A) $E_{\text {const }}$ with $I$ in $\mathrm{KBr}$, (B) $E_{\text {const }}-E_{1}$ with $I$ in $\mathrm{KBr}$, (C) $E_{\text {const }}$ with $I$ in $\mathrm{NaCl}$, and (D) $E_{\text {const }}-E_{1}$ with $I$ in $\mathrm{NaCl}$. The solid line represents the variation of $s \log \gamma_{\mathrm{H}}{ }^{+}$with $I$ according to the Pitzer equations.

There are few reported liquid junction potentials. By exception, Bagg [15] has reported the potentials for the junction or free diffusion between a $4 \mathrm{M} \mathrm{KCl}$ solution and $\mathrm{NaCl}$ or $\mathrm{KBr}$ solutions at a variable ionic strength (Fig. 6). The results of Bagg [15] for the liquid junction residual potential in dual-junction cells are comparable, within experimental error for this type of measurement, with those experimentally-derived in almost every system studied so far. As noted by Bagg himself, 'this agreement is particularly satisfactory in view of (a) the probable differences of the junctions, sleevetype and frit, used in the cells from the idealized model of junction used in the calculation, and (b) the extrapolation of some transference numbers beyond the range of concentration in which they are determined.' 


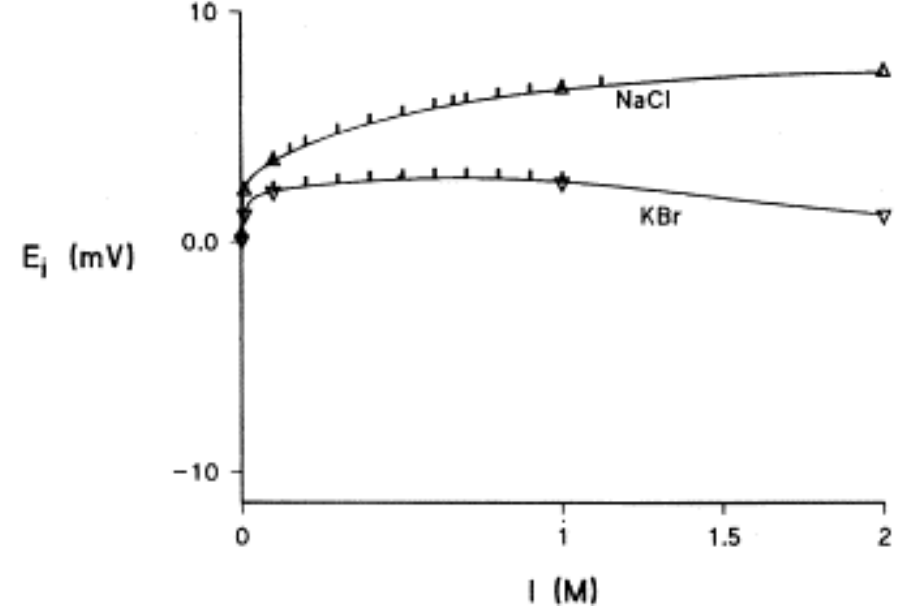

Fig. 6.

Variation of $E_{1}$ with $I$ in $\mathrm{NaCl}$ and $\mathrm{KBr}$. Triangles represent data from an earlier reference [15] and ticks the points where $E_{1}$ was extrapolated.

The sole constraint to the use of the previous data [15] is that the ionic strength values used do not coincide with those of our experiments, so $E_{1}$ must be interpolated to the desired $I$ values. For this purpose, we used a polynomial ratio proposed elsewhere [16] as the interpolation function. We used this type of function because it fits the experimental behaviour more closely than does a simple polynomial or a cubic spline interpolation function [16].

Provided the liquid junction potential is known, Eq. (2) can be rewritten as

$$
E_{\text {const }}-E_{1}=E_{\mathrm{t}}+E_{g}^{0}+s \log \gamma_{\mathrm{H}}+
$$

If the only term that depends on ionic strength on the right-hand side of this equation is the activity coefficient for the proton, then, the plots of $\left(E_{\text {const }}-E_{1}\right)$ versus $I$ and $\left(s \log \left[\mathrm{H}^{+}\right]\right)$versus $I$ should exhibit the same trend except for the shift due to the $\left(E_{\mathrm{r}}+E_{\mathrm{g}}^{0}\right)_{\text {term. }}$ In order to confirm this assumption, we superimposed the $\left(s \log \gamma_{\mathrm{H}}^{+}\right)$versus $I$ curve and shifted it to overlap the previous one, obviously, at the same scale amplitude $(20 \mathrm{mV})$ in both cases ( Fig. 5B,D).

The activity coefficient for the proton was calculated in the light of Pitzer's formalism. The pertinent equations are given in Appendix Aand the curves obtained in the different electrolytes studied are shown inFig. 7. As can be seen, every curve exhibits a minimum at a different ionic strength for each electrode, beyond which the curve is virtually linear. The similar behaviour of the $\left(s \log {\gamma_{\mathrm{H}}}^{+}\right)$versus $I$ curves and the $\left(E_{\text {const }}-E_{1}\right)$ versus $I$ curves is apparent in Fig. 5B,D for $\mathrm{KBr}$ and $\mathrm{NaCl}$, respectively. One quantitative way of comparing the experimental results with the curve derived from the Pitzer equations is by fitting experimental $E_{\text {const }}$ versus $I$ data points and those in the $\left(s \log {\gamma_{\mathrm{H}}}^{+}\right)$versus $I$ curve obtained from the Pitzer equations - obviously in the virtually linear zone ( Fig. 7) - to a straight line. Table 1 gives the results obtained and the ionic strength range used in each fitting. As can be seen, consistency between data is quite good for $\mathrm{KBr}$ (Fig. 5B) but not quite for $\mathrm{NaCl}$ ( Fig. 5D) as the likely result of $\mathrm{Na}^{+}$ion influencing the behaviour of the glass electrode. Unfortunately, there seems to be no 
reported liquid junction potentials for the other systems studied, so we chose to plot $E_{\text {const }}$ versus $I$ and $\left(s \log {\gamma_{\mathrm{H}}}^{+}\right)$versus $I$ in the same graphs.

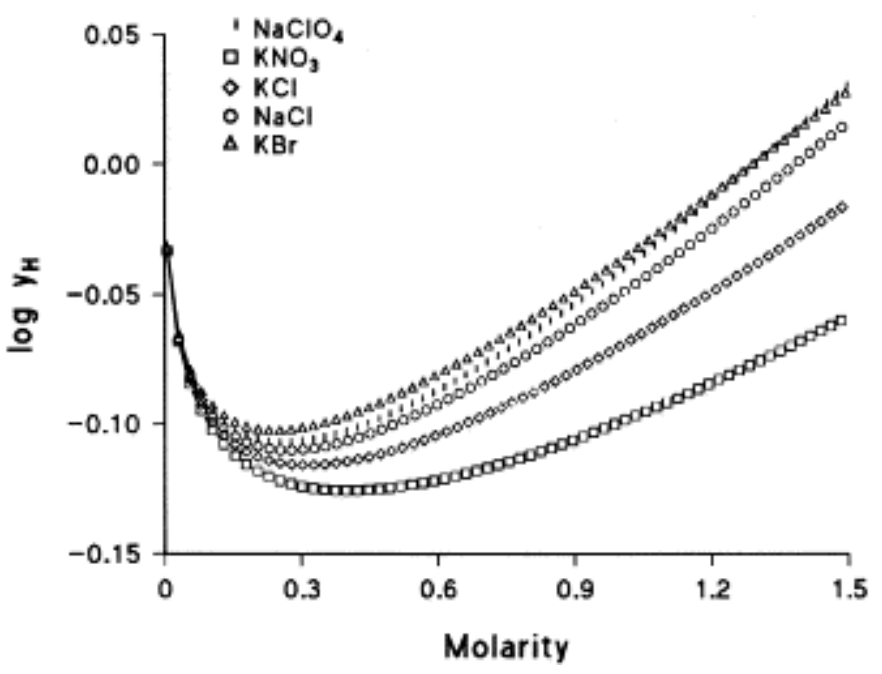

Fig. 7.

Variation of $\log \gamma_{\mathrm{H}}{ }^{+}$with $I$ (on the molar scale) in $\mathrm{NaClO}_{4}, \mathrm{KNO}_{3}, \mathrm{KCl}$, $\mathrm{NaCl}$ and $\mathrm{KBr}$.

Table 1.: Slopes of the linear fits of $E_{\text {const }}$ versus $I,\left(E_{\text {const }}-E_{1}\right)$ versus $I$ and $\operatorname{slog} \gamma_{\mathrm{H}}{ }^{+}$versus $I$ plots in each of the electrolytes studied

\begin{tabular}{|l|l|l|l|l|l|}
\hline Electrolyte & $59.16 \times \log y^{\mathrm{a}}$ (Pitzer eq.) & Slope of $E_{\text {const }}$ vs. $I$ & Slope of $E_{\text {const }}-E_{1}$ vs. $I$ & $I$ range & Fig. \\
\hline $\mathrm{KNO}_{3}$ & $4.0 \pm 0.1$ & $4.8 \pm 0.7$ & $0.5-1.5$ & $2 \mathrm{a}$ \\
\hline & $4.0 \pm 0.1$ & $5.1 \pm 0.6$ & $0.5-1.5$ & $2 \mathrm{~b}$ \\
\hline & $4.0 \pm 0.1$ & $3.7 \pm 0.6$ & $0.5-1.5$ & $2 \mathrm{c}$ \\
\hline & $4.0 \pm 0.1$ & $5.7 \pm 0.8$ & $0.5-1.5$ & $2 \mathrm{e}$ \\
\hline $\mathrm{KCl}$ & $4.0 \pm 0.1$ & $5.0 \pm 0.3$ & $0.5-1.5$ & $2 \mathrm{f}$ \\
\hline $\mathrm{NaClO}$ & $6.2 \pm 0.1$ & $6.7 \pm 0.6$ & $0.5-1.5$ & $4 \mathrm{a}$ \\
\hline $\mathrm{KBr}$ & $6.5 \pm 0.1$ & $9.9 \pm 1.4$ & $0.5-1.0$ & $4 \mathrm{~b}$ \\
\hline $\mathrm{NaCl}$ & $6.0 \pm 0.1$ & $6.6 \pm 1.5$ & $6.8 \pm 1.4$ & $0.5-1.0$ & $5 \mathrm{a}, \mathrm{b}$ \\
\hline
\end{tabular}

a Obtained from those points in Fig. 7 that lay within the stated ionic strength range for each electrolyte. 
As can be seen from both Table 1 and Fig. 5A, the results in $\mathrm{KBr}$ were still similar, which was to be expected since $E_{1}$ remained virtually constant throughout the ionic strength range studied. Similar consistency was observed in $\mathrm{KCl}$ and $\mathrm{KNO}_{3}$ ( Table 1, Fig. 2 and Fig. 4A), which suggests that $E_{1}$ remains virtually constant over the ionic strength range where the formal potential was determined. Fig. 2 also shows six data series for the formal potential; while all exhibit a similar trend, the potential is displaced to a greater or lesser extent between one another. Based on Eq. (5), this can be ascribed

to change in the $\left(E_{\mathrm{t}}+E_{\mathrm{g}}^{0}\right)$ term because, if the electrodes were theoretically immersed in the same solutions, $E_{\mathrm{r}}$ should have remained constant and the change be due to a variation in the asymmetry potential with time typical of changes at the electrode surface layer.

The $E_{\text {const }}$ versus $I$ plot in sodium perchlorate exhibited a much greater slope than that obtained from the Pitzer fitting as the likely result of (a) the influence of sodium ion on glass membranes and/or (b) a major change in the liquid junction potential relative to potassium salts over the ionic strength range studied.

\section{Appendix A.}

The relationship of $\log \gamma_{\mathrm{H}}{ }^{+}$to $I$ was studied in the light of the Pitzer equations [17], which have frequently been used to describe the influence of ionic strength on the activity coefficients for strong electrolytes at moderate to high concentrations and a high electrolyte concentration. Our group has used them to interpret the variation with ionic strength of the acidity constants for some organic molecules 18, 19, 20, 21, 22, 23,24, 25 and 26.

Based on Pitzer's formalism, the activity coefficient for $\mathrm{H}^{+}$ion in the presence of excess electrolyte is given by

$$
\ln \gamma_{\mathrm{H}}+=f^{\gamma}+2 I\left(B_{\mathrm{XH}}+I C_{\mathrm{XH}}\right)+I^{2}\left(B_{X \mathrm{~K}}^{\prime}+C_{X \mathrm{~K}}\right)+I\left(2 \theta_{H \mathrm{~K}}+I \psi_{\mathrm{HXK}}\right)
$$

where the ionic strength is determined from the salt concentration since the salt is in a large excess relative to the proton. $f^{\prime}, B$ and $B^{\prime}$ depend on $I$, as can be seen in the following equations:

$$
\begin{gathered}
f^{\gamma}=-A_{\phi}\left[\frac{\sqrt{I}}{1+1.2 \sqrt{I}}+\frac{2}{1.2} \ln (1+1.2 \sqrt{I})\right] \\
B_{X \mathrm{~K}}=\beta_{X \mathrm{~K}}^{(0)}+\frac{\beta_{X \mathrm{KK}}^{(1)}}{2 I}[1-(1+1.2 \sqrt{I}) \exp (-2 \sqrt{I})]
\end{gathered}
$$




$$
\beta_{X \mathrm{~K}}^{\prime}=\beta_{X \mathrm{XK}}^{(0)}+\frac{\beta_{X \mathrm{X}}^{(1)}}{2 I}[-1+(1+1.2 \sqrt{I}+2 I) \exp (-2 \sqrt{I})]
$$

Substituting $B$ and $B^{\prime}$ in the expression for the logarithm of the activity coefficient of $\mathrm{H}^{+}$ion yields

$$
\ln \gamma_{\mathrm{H}}+=f^{\gamma}+P I+Q I^{2}+R I \mathrm{e}^{-2 \sqrt{I}}+T\left[1-(1+1.2 \sqrt{I}) \mathrm{e}^{-2 \sqrt{I}}\right]
$$

where

$$
\begin{gathered}
P=2\left(\beta_{\mathrm{H} X}^{(0)}+\theta_{\mathrm{HK}}\right) \\
Q=C_{\mathrm{H} X}^{\phi}+\frac{C_{\mathrm{K} X}^{\phi}}{2}+\psi_{\mathrm{H} X \mathrm{~K}} \\
R=\beta_{K X}^{(1)} \\
T=\beta_{\mathrm{H} X}^{(1)}-\frac{\beta_{\mathrm{K} X}^{(1)}}{2}
\end{gathered}
$$

$\mathrm{P}, \mathrm{Q}, \mathrm{R}$ and $\mathrm{T}$ are thus constants that depend on the particular inert electrolyte (see Table 2). The Pitzer parameters used to calculate them were taken from an earlier reference [17].

Table 2. Pitzer Parameters used in Eq. (A.5)for each of the electrolytes studied

\begin{tabular}{|ll|l|l|l|}
\hline Electrolyte & $P$ & $Q$ & $R$ & $T$ \\
\hline $\mathrm{KNO}_{3}$ & 0.2338 & 0.0043 & 0.0494 & 0.2959 \\
\hline $\mathrm{KCl}$ & 0.3650 & -0.0062 & 0.2122 & 0.1884 \\
\hline $\mathrm{KBr}$ & 0.4020 & -0.01363 & 0.2212 & 0.2458 \\
\hline $\mathrm{NaCl}$ & 0.4270 & -0.0026 & 0.2664 & 0.1613 \\
\hline $\mathrm{NaClO}_{4}$ & 0.4214 & -0.00899 & 0.2755 & 0.15535 \\
\hline
\end{tabular}


The activity coefficients in Eq. (A.5)are expressed on the molal scale, so they must be converted into molar units since $E_{\text {const }}$ was determined from molar $\left[\mathrm{H}^{+}\right]$values. We used the following equation for this purpose[27]:

$$
y=\gamma \frac{\rho_{\mathrm{w}}}{\rho}\left(1+\sum_{i} m_{i} \cdot M_{i}\right)
$$

where $y$ and $\gamma$ denote the activity coefficients on the molar and molal scale, respectively; $\rho$ is the solution density; $\rho_{\mathrm{w}}$ is water density at the working temperature; $i$ denotes any ion in solution; and $M i$ is the molar mass of ion $i, m i$ is molality and $c i$ its molarity.

By way of example, substituting water density at $25^{\circ} \mathrm{C}$ and the molecular mass of $\mathrm{NaCl}$ into Eq. (A.7) yields

$$
y_{\mathrm{NaCl}}=\frac{\gamma_{\mathrm{NaCl}}}{\rho_{\mathrm{NaCl}}}\left(0.997075+0.05827 \mathrm{~m}_{\mathrm{NaCl}}\right)
$$

Also, molality can be converted into molarity by using the following expression:

$$
\frac{c}{m}=\frac{\rho_{\mathrm{NaCl}}}{1+\sum_{i} m_{i} \cdot M_{i}}
$$

which, for $\mathrm{NaCl}$, becomes

$$
c_{\mathrm{NaCl}}=\frac{\rho_{\mathrm{NaCl}} m_{\mathrm{NaCl}}}{1+0.10110 m_{\mathrm{NaCl}}}
$$

The dependence of density on the ionic strength can be determined by fitting $\rho$ versus $m$ data pairs to a polynomial expression of $m$ based on reported values 28 and 29.

\section{References}

1. E.P. Serjeant

Potentiometry and Potentiometric TitrationsWiley, New York (1984)

2. A. Braibanti, G. Ostaroli, P. Paoleti, D. Petit, S. Sammartano

Pure Appl. Chem., 59 (12) (1987), p. 1721

3. P.M. May, D.R Williams, P.W. Linder, R.G. Torrington

Talanta, 29 (1982), p. 249

4. P.W. Linder, R.G. Torrington, D.R. Williams

Analysis using Glass Electrodes, Ch. 4Open University Press, Oxford (1984) 
5. S. Fiol, F. Arce, X.L. Armesto, F. Penedo, M. Sastre de Vicente Fresenius J. Anal. Chem., 343 (1992), p. 469

6. H. Galster pH MeasurementVCH, New York (1991)

7. W.A.E. Mcbryde, Analyst, 96 (1971) p. $739 ; 94$ (1969) p. 337.

8. H.S. Dunsmore, D. Midley Anal. Chim. Acta, 61 (1972), p. 115

9. M.T.S.D. Vasconcelos, A.S.C. Machado Rev. Port. Quim., 28 (1986), p. 120

10. E.W. Baumann Anal. Chim. Acta, 64 (1973), p. 284

11. H.M. Irving, M.G. Miles, L.D. Petit Anal. Chim. Acta, 38 (1967), p. 475

12. G.R. Hedwig, H.K.J. Powell Anal. Chem., 43 (10) (1971), p. 1206

13. L. Pezza, M. Molina, M. de Moraes, C.B. Melios, J.O. Tognolli Talanta, 43 (1996), p. 1689

14. W.H. Beck, J. Caudle, A.K. Covington, W.F.K. Wynne-Jones, Proc. Chem. Soc., (1963) 110.

15. J. Bagg

Electrochim. Acta, 35 (2) (1990), pp. 361-367

16. W.H. Press, S.A. Teukolsky, W.T. Veterling, B.P. Flannery

Numerical Recipes in Fortran Ch., 3 (2nd ed.)Cambridge University Press, Cambridge (1992)

17. K.S. Pitzer

Theory: ion interaction approach

K.S. Pitzer (Ed.), Activity Coefficients in Electrolyte Solutions. (2), CRC Press, Boca Ratón, Fl (1991), p. 75

18. R. Herrero, X.L. Armesto, F. Arce, M. Sastre de Vicente

J. Solution Chem., 21 (11) (1992), p. 1185

19. I. Brandariz, F. Arce, X.L. Armesto, F.J. Penedo, M. Sastre de Vicente Monatsh. Chem., 124 (1993), p. 249

20. R. Herrero, I. Brandariz, M. Sastre de Vicente 
Ber. Bunsenges. Phys. Chem., 97 (1) (1993), p. 59

21. I. Brandariz, R. Herrero, M. Sastre de Vicente

J. Chim. Phys., 90 (1993), p. 63

22. H. Herrero, I. Brandariz, S. Fiol, M. Sastre de Vicente

Collect. Czech. Chem. Commun., 58 (1993), p. 1269

23. S. Fiol, I. Brandariz, X.L. Armesto, F. Arce, M. Sastre de Vicente Ann. Chim. (Rome), 83 (1993), p. 175

24. I. Brandariz, S. Fiol, R. Herrero, T. Vilariño, M. Sastre de Vicente

J. Chem. Eng. Data, 38 (1993), p. 531

25. S. Fiol, I. Brandariz, R. Herrero, T. Vilariño, M. Sastre de Vicente Ber. Bunsenges. Phys. Chem., 98 (1994), p. 164

26. R. Herrero, I. Brandariz, S. Fiol, T. Vilariño, M. Sastre de Vicente An. Quím., 89 (5) (1993), p. 602

27. F. Macintyre

Mar.Chem., 4 (1970), p. 205

28. R.C. Weast (ed.), C.R.C. Handbook of Chemistry and Physics, C.R.C. Press, Boca Raton, Florida, 1986,

29. J.F. Chem, G.R. Choppin

J. Solution Chem., 24 (5) (1995), p. 46

Corresponding author. Tel.:+34 81 167050; fax:+34 81 167065; e-mail: eman@udc.es

If calibration was performed by adding a base to an acid solution, then the combination of relatively small errors in the concentration of both resulted in the slope of the fitted curve deviating from the Nernstian value, as previously noted elsewhere 3 and 5. 